The ASTROPHYSICAL JouRNAL, 536:347-356, 2000 June 10

(c) 2000. The American Astronomical Society. All rights reserved. Printed in U.S.A.

\title{
AN INVENTORY OF INTERSTELLAR ICES TOWARD THE EMBEDDED PROTOSTAR W33A ${ }^{1}$
}

\author{
E. L. Gibb, ${ }^{2,3}$ D. C. B. Whittet, ${ }^{2,3}$ W. A. Schutte, ${ }^{4}$ A. C. A. Boogert,${ }^{5,6}$ J. E. Chiar, ${ }^{7}$ P. Ehrenfreund, ${ }^{4}$ \\ P. A. Gerakines, ${ }^{2,8}$ J. V. Keane, ${ }^{5}$ A. G. G. M. Tielens, ${ }^{5}$ E. F. van Dishoeck, ${ }^{4}$ and O. Kerkhof ${ }^{4}$ \\ Received 1999 December 7; accepted 2000 January 27
}

\begin{abstract}
This paper presents, for the first time, a complete 2.4-25 $\mu \mathrm{m}$ spectrum of the dust-embedded young stellar object W33A. The spectrum was obtained with the Short Wavelength Spectrometer of the Infrared Space Observatory at a mean resolving power of $\sim 750$. The spectrum displays deep $\mathrm{H}_{2} \mathrm{O}$ ice and silicate absorptions centered at 3.0 and $9.7 \mu \mathrm{m}$, respectively, together with absorption features identified with various other molecules in the solid phase. The 2.4-5.0 $\mu \mathrm{m}$ region of the spectrum is used to investigate the long-standing problem of the $\mathrm{H}_{2} \mathrm{O}$ ice column density toward $\mathrm{W} 33 \mathrm{~A}$, by means of the stretching and combination mode features at 3.0 and $4.5 \mu \mathrm{m}$. Although no flux is seen at the center of the $3.0 \mu \mathrm{m}$ feature, its central depth may be constrained by fitting assumed profiles to the short- and longwavelength wings in our spectrum. We deduce that a value of $N\left(\mathrm{H}_{2} \mathrm{O}\right)=(1.1 \pm 0.3) \times 10^{19} \mathrm{~cm}^{-2}$ is consistent with these features, a factor of at least 3 less than predicted by the $\mathrm{H}_{2} \mathrm{O}$ bending mode at $6.0 \mu \mathrm{m}$; the reason for this discrepancy is unclear. We report new results on the abundances of nitrogen-bearing species in the ices toward W33A. Solid $\mathrm{NH}_{3}$ is detected for the first time in this line of sight, by means of the inversion-mode feature at $9.0 \mu \mathrm{m}$. The column density is $N\left(\mathrm{NH}_{3}\right)=(1.7 \pm 0.4) \times 10^{18} \mathrm{~cm}^{-2}$, implying an abundance of $\sim 15 \%$ relative to $\mathrm{H}_{2} \mathrm{O}$, comparable to that recently reported toward the young star NGC 7538 IRS 9. However, we find no convincing evidence for absorptions associated with the $\mathrm{C} \equiv \mathrm{N}$ stretching mode of nitriles in the 4.4-4.6 $\mu \mathrm{m}$ region of the spectrum. If nitriles are present in the ices along this line of sight, they must have column density no more than $\sim 10^{17} \mathrm{~cm}^{-2}$ or $\sim 1 \%$ relative to $\mathrm{H}_{2} \mathrm{O}$. This argues against identification of the deep $4.62 \mu \mathrm{m}$ 'XCN' feature with isonitriles, as an implausibly low nitrile to isonitrile abundance ratio $(<0.1)$ would be implied. New and previously published results are combined to construct an inventory of column densities and abundances (normalized to $\mathrm{H}_{2} \mathrm{O}$ ) for all known species detected in molecular ices toward W33A. A band strength appropriate to the cyanate ion is assumed to provide quantitative results for XCN. Results are compared with those for other well-studied lines of sight, including the Taurus field star Elias 16, the Galactic center source Sgr A*, and the young stellar objects NGC 7538 IRS 9, GL 2136, and GL 7009S. The CO and $\mathrm{XCN}$ abundances are used as indicators of thermal and energetic processing, respectively (where energetic processing may include either UV photolysis or energetic ion bombardment). Abundances for $\mathrm{CH}_{3} \mathrm{OH}$ vary from below $3 \%$ in unprocessed ices to $\sim 20 \%-30 \%$ in W33A and GL $7009 \mathrm{~S}$, consistent with formation by energetic processing. In contrast, $\mathrm{CH}_{4}$ shows little evidence of variation. Abundance data for cometary ices indicate some general similarities with interstellar and protostellar ices. $\mathrm{CO}$ and $\mathrm{CH}_{3} \mathrm{OH}$ show comet-to-comet variations that may provide clues to their origins. The highest $\mathrm{CH}_{3} \mathrm{OH}$ concentrations in comets are comparable with average values for interstellar/protostellar ices.
\end{abstract}

Subject headings: dust, extinction — infrared: ISM: lines and bands - ISM: individual (W33A) ISM: molecules

\section{INTRODUCTION}

The infrared spectra of young stellar objects (YSOs) embedded within cold, dense envelopes display solid-state absorption features characteristic of molecular ices pre-

\footnotetext{
${ }^{1}$ Based on observations with ISO, an ESA project with instruments funded by ESA Member States (especially the PI countries: France, Germany, the Netherlands, and the United Kingdom) and with the participation of ISAS and NASA.

${ }^{2}$ Department of Physics, Applied Physics \& Astronomy, Rensselaer Polytechnic Institute, Troy, NY 12180.

${ }^{3}$ New York Center for Studies on the Origins of Life, Rensselaer Polytechnic Institute, Troy, NY 12180.

${ }^{4}$ Leiden Observatory, P.O. Box 9513, 2300 RA Leiden, The Netherlands.

${ }^{5}$ Kapteyn Astronomical Institute, P.O. Box 800, 9700 AV Groningen, The Netherlands.

${ }^{6}$ Present address: Department of Physics, California Institute of Technology, Pasadena, CA 91125.

7 NASA Ames Research Center, Mail Stop 245-3, Moffett Field, CA 94035, and SETI Institute, Mountain View, CA 94043.

${ }^{8}$ Present address: NASA Goddard Space Flight Center, Code 691, Greenbelt, MD 20771.
}

sumed to exist as mantles on dust grains (e.g., Merrill, Russell, \& Soifer 1976; Willner et al. 1982). Among such known objects, W33A is notable as having a particularly rich solid-state molecular spectrum. The underlying source of radiation is generally assumed to be a massive, luminous YSO within the W33 H II region/molecular cloud complex, situated at a distance of $\sim 4 \mathrm{kpc}$ from the Sun and hidden by 50-150 magnitudes of visual extinction (Capps, Gillett, \& Knacke 1978; Goss, Matthews, \& Winneberg 1978; Mitchell et al. 1990). The spectrum of W33A is dominated by extremely deep solid-state absorption features of $\mathrm{H}_{2} \mathrm{O}$ ice and silicates, centered near 3.1 and $9.7 \mu \mathrm{m}$, respectively (Capps et al. 1978). Other molecular ices detected in this line of sight include $\mathrm{CO}, \mathrm{CO}_{2}, \mathrm{OCS}, \mathrm{CH}_{3} \mathrm{OH}, \mathrm{CH}_{4}$, and a $\mathrm{CN}$ bearing species referred to generically as " $\mathrm{XCN}$ " (Willner et al. 1982; Lacy et al. 1984; Grim et al. 1991; Tielens et al. 1991; Allamandola et al. 1992; Palumbo, Tielens, \& Tokunaga 1995; Boogert et al. 1996; Gerakines et al. 1999; Pendleton et al. 1999). Ices in the line of sight to W33A appear to have undergone significant evolution compared with 


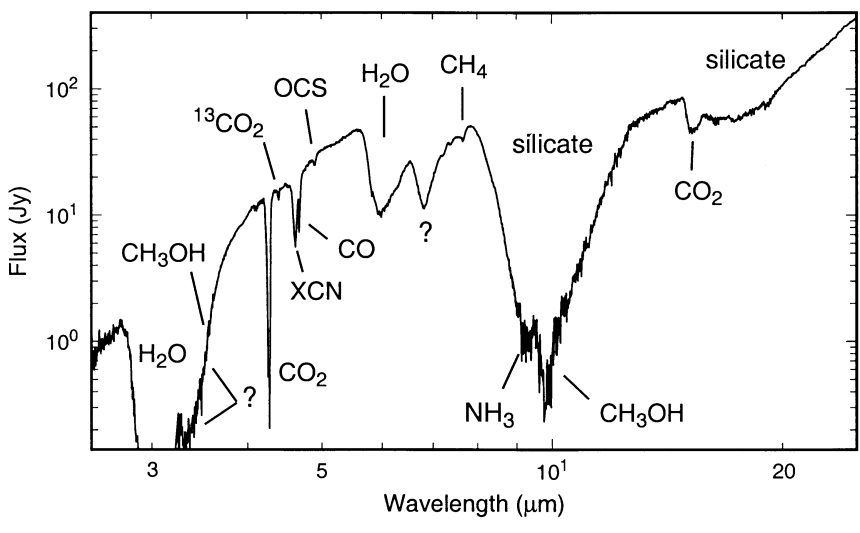

Fig. 1.-Complete 2.4-25 $\mu \mathrm{m}$ SWS flux spectrum of W33A. The observations were made in mode S01 (speed 4) with a resolving power of $\sim 500$ 1000. The principal identified and unidentified spectral features are labelled. Detections of $\mathrm{NH}_{3}$ and $\mathrm{CH}_{3} \mathrm{OH}$ features near $10 \mu \mathrm{m}$ are reported in $\S 4$.

those in cold, quiescent molecular clouds. $\mathrm{CO}$, the most volatile of the molecules commonly detected in grain mantles, is predominantly in the gas phase (Mitchell, Allen \& Maillard 1988; Mitchell et al. 1990). The profile shapes of solid-state features arising in both $\mathrm{CO}$ and $\mathrm{CO}_{2}$ give evidence for partial evaporation and/or annealing of the mantles (Chiar et al. 1998; Gerakines et al. 1999; Boogert et al. 2000), and the carrier of the XCN feature seems likely to be a product of energetic processing (UV photolysis and/or energetic ion bombardment; e.g., Grim \& Greenberg 1987; Bernstein et al. 1995; Schutte \& Greenberg 1997; Demyk et al. 1998; Palumbo et al. 2000).

Studying the composition and structure of ices as functions of physical environment is vital to gaining an understanding of chemical evolution in protostellar envelopes. Detailed studies of the solid-state molecular inventories in sources such as W33A will provide an important database for comparison with primitive solar system material such as comets, and for constraining models of nebular chemistry. To this end, we present in $\S 2$ the complete $2-25 \mu \mathrm{m}$ spectrum of W33A, as observed with the Short Wavelength Spectrometer (SWS) of the Infrared Space Observatory (ISO). The question of the $\mathrm{H}_{2} \mathrm{O}$ ice abundance toward

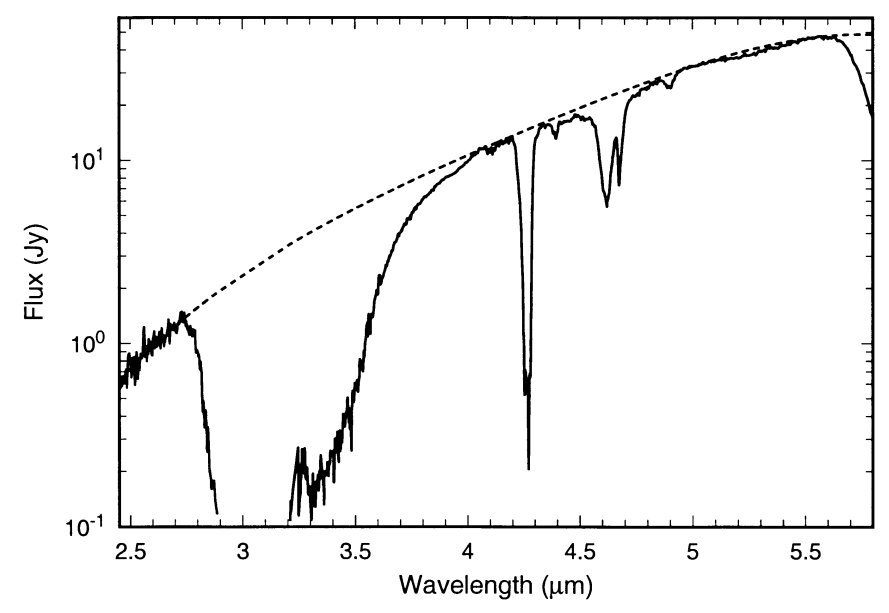

FIG. 2.-The 2.4-6 $\mu \mathrm{m}$ flux spectrum of W33A (solid curve) with the adopted continuum fit (dashed curve).
W33A is addressed in $\S 3$, and first detection of $\mathrm{NH}_{3}$ ice in this line of sight is reported in $\S 4$. A new constraint on the abundance of nitriles is presented in $\S 5$. Solid-state column densities and abundances for all identified species toward W33A are tabulated in $\S 6$ and compared with results for other lines of sight. Conclusions and suggestions for future research are summarized in the final section.

\section{THE ISO SWS SPECTRUM OF W33A}

W33A (R.A. $18^{\mathrm{h}} 14^{\mathrm{m}} 39^{\mathrm{s}} .4$, decl. $-17^{\circ} 52^{\prime} 01^{\prime \prime}$, J2000) was observed by the ISO SWS on 1996 October 10, during revolution 329 of the mission. The SWS was used in mode S01 (speed 4), covering the entire spectral range available with this instrument $(2.4-45 \mu \mathrm{m})$ at a resolving power $\sim R / 2$ (where $R$, the full resolving power of the SWS, ranges from 1000 to 2000). ${ }^{9}$ A detailed description of the SWS and its mode of operation is given by de Graauw et al. (1996). The data were reduced at the Infrared Processing and Analysis Center (IPAC) in Pasadena, CA, using the standard SWS Interactive Analysis package (de Graauw et al. 1996) and the latest available pipeline process (OLP V7.0).

Figure 1 shows the flux spectrum of W33A in the wavelength range (2.4-25 $\mu \mathrm{m})$ of interest for solid-state features. The principal features are labeled with their identification, where known. The $25-45 \mu \mathrm{m}$ spectrum (not shown) exhibits a smoothly rising continuum with no discernible spectral features.

Because of low flux levels, the SWS spectrum of W33A is extremely noisy near the centers of the deep features at 2.8-3.3 $\mu \mathrm{m}\left(\mathrm{H}_{2} \mathrm{O}\right.$ ice) and 8-12 $\mu \mathrm{m}$ (silicates). To improve the situation, two quality-control "filters" were applied. Individual points were rejected if either of the following statements are true: (1) the signal-to-noise ratio, as determined in the standard pipeline reduction procedure, is less than 3; and (2) the flux level is less than $0.1 \mathrm{Jy}$. The second filter is needed because the SWS data are generally unreliable at flux levels below $0.1 \mathrm{Jy}$, even when the nominal signal-to-noise ratio is reasonable. This procedure has been applied to the data presented in Figure 2 (below) and all subsequent plots.

A recurrent problem in the study of solid-state features is determination of the appropriate continuum baseline needed to convert flux spectra to optical depth spectra. The nature of the problem can be discerned from Figure 1: many of the features are broad and overlapping, and it is difficult to be certain which segments of the spectrum are pure continuum. Many of the features in W33A are sufficiently deep that small errors in the chosen continuum level will not greatly affect the profile shape or abundance estimates, but the problem is more serious in the case of shallow features (such as the $\mathrm{H}_{2} \mathrm{O}$ combination mode: see $\S 3.2$ ). A common approach in studies that focus on an individual feature is to fit a continuum to that feature in isolation. Indeed, in the past, this approach has been dictated to some extent by the limited spectral coverage afforded to ground-based observations by the Earth's atmosphere. We seek here to define a global continuum for the spectral range $2.4-6 \mu \mathrm{m}$ in W33A. A fourth-order poly-

\footnotetext{
${ }^{9}$ Note that a number of mode S06 observations of W33A are also available. These give full SWS resolution over shorter spectral segments and are generally targeted to specific features. Details of these observations are presented elsewhere (Boogert et al. 1996, 1998, 2000; Gerakines et al. 1999; Schutte et al. 1999; Keane et al. 2000a); many of the results are included in the inventory presented in $\S 6$ (Table 1 ).
} 
nomial was fit to the spectrum, assuming the segments 2.4 $2.7,4.0-4.1,4.95-5.1$, and $5.5-5.6 \mu \mathrm{m}$ to lie on the continuum. The fit is shown in Figure 2; this continuum was used to derive optical depth spectra discussed in the following section.

\section{THE $\mathrm{H}_{2} \mathrm{O}$ ICE COLUMN DENSITY}

$\mathrm{H}_{2} \mathrm{O}$ is the most abundant of all molecules commonly condensed into grain mantles in molecular clouds, and it dominates the major (polar) phase of the ices (e.g., Tielens et al. 1991). However, the column density of $\mathrm{H}_{2} \mathrm{O}$ ice toward W33A is controversial, values quoted in the literature ranging (in units of $10^{19} \mathrm{~cm}^{-2}$ ) from 0.9 to 4.7. The lesser value was estimated from ground-based spectra of the 3.1 $\mu \mathrm{m}\left(3225 \mathrm{~cm}^{-1}\right) \quad \mathrm{O}-\mathrm{H}$ stretching mode of $\mathrm{H}_{2} \mathrm{O}$ (Allamandola et al. 1992), the greater from observations of the $6.0 \mu \mathrm{m}\left(1670 \mathrm{~cm}^{-1}\right)$ bending mode with the Kuiper Airborne Observatory (Tielens et al. 1984). With the availability of ISO SWS data, it is timely to reexamine this question.

\subsection{Stretching Mode}

As previously noted, little flux is detected near the center of the $\mathrm{O}-\mathrm{H}$ stretching mode feature of $\mathrm{H}_{2} \mathrm{O}$ ice at $3.05 \mu \mathrm{m}$ in W33A, owing to the strength of the absorption feature itself and the intrinsic weakness of the source continuum in the near-infrared. Allamandola et al. (1992) estimated the depth of this feature in W33A by comparing the 3.3-3.6 $\mu \mathrm{m}$ wing of the profile in ground-based spectra with profiles observed in other protostars. We adopt a similar technique, using spectra of laboratory ices as well as astronomical sources for comparison. The unique advantage of the SWS is that it delineates the wings shortward as well as longward of the band center in W33A, whereas the shortward wing is lost to atmospheric absorption in ground-based spectra. Interpretation is complicated by the fact that other likely constituents of interstellar ices contribute to the overall $3 \mu \mathrm{m}$ absorption profile. The short-wavelength wing may be deepened by the $2.95 \mu \mathrm{m} \mathrm{N}-\mathrm{H}$ stretching mode of ammonia. The long-wavelength wing, which extends from $3.3 \mu \mathrm{m}$ to at least $3.8 \mu \mathrm{m}$, is generally attributed to scattering by large ice-mantled grains and/or absorptions in organic molecules $(\mathrm{C}-\mathrm{H}$ stretching mode) or ammonium hydrate complexes; its structure and strength relative to the main feature can change substantially from one line of sight to another (e.g., Smith, Sellgren, \& Tokunaga 1989).

The 2.5-4.1 $\mu \mathrm{m}$ optical depth spectrum of W33A is shown in Figures $3 a-3 d$, together with various comparisons. To provide an astronomical comparison profile, we constructed optical depth plots in the same spectral range for several YSOs, observed with the SWS in the same mode (S01 speed 4) as W33A (Nummelin et al. 2000): the sources chosen were S140, NGC 7538 IRS 1, GL 490, and Elias 29. Figure 4 shows the average profile, normalized to unit peak optical depth and smoothed to a resolution of $0.02 \mu \mathrm{m}$. Also shown for comparison are corresponding ground-based data from Smith et al. (1989) for an independent set of YSOs. ${ }^{10}$ The SWS and ground-based profiles agree very well: the only appreciable difference occurs in the 3.26-3.32 $\mu \mathrm{m}$ region, where the ground-based data are subject to imperfectly cancelled telluric methane absorption; also, one source (NGC 7538 IRS 1) in the SWS sample is affected by

\footnotetext{
${ }^{10}$ The sources included from Smith et al. (1989) are BN, GL 961, GL 989, GL 2591, Mon R2 IRS 2, Mon R2 IRS 3, S255 IRS 1, and W3 IRS 5
}

nebular emission at $\sim 3.29 \mu \mathrm{m}$ from polycyclic aromatic hydrocarbons.

Figures $3 a$ and $3 b$ show representative attempts to match the wings of the ice feature in W33A with the average profile for YSOs observed with the SWS (Fig. 4). The normalized profile is simply scaled by a multiplicative constant until a reasonable match is obtained: this was done by eye as the data do not warrant a more sophisticated approach. It is not possible to obtain a perfect fit to the slope of the shortwavelength wing or to match the long- and shortwavelength wings simultaneously with any curve. It may be the case that the long-wavelength wing in W33A is unusually deep relative to the main ice feature, compared with the "average" source. In Figure $3 b$, we also compare W33A with data for Mon R2 IRS 3, the source in the Smith et al. (1989) sample with the most pronounced longwavelength wing; however, inspection shows that this profile is no more successful than the mean profile in matching the feature in W33A on the short-wavelength side. We therefore rely on the mean profile comparison to make an estimate of the peak optical depth and the $\mathrm{H}_{2} \mathrm{O}$ column density. Considering a range of possible matches to the short-wavelength profile, as illustrated in Figure $3 a$, we conclude that the most probable value of the central optical depth is $\tau_{\max }=5.5 \pm 1.5$. Adopting a band strength of $A=2.0 \times 10^{-16} \mathrm{~cm}$ per molecule (Gerakines et al. 1995), the estimated column density is $N\left(\mathrm{H}_{2} \mathrm{O}\right)=\int \tau_{v} d v / A=(1.0$ $\pm 0.3) \times 10^{19} \mathrm{~cm}^{-2}$. This is in agreement with the earlier estimate of Allamandola et al. (1992), also based on the $3 \mu \mathrm{m}$ feature.

Comparisons based on laboratory ices are shown in Figures $3 c$ (pure $\mathrm{H}_{2} \mathrm{O}$ ice) and $3 d\left(\right.$ a $100: 9 \mathrm{H}_{2} \mathrm{O}: \mathrm{NH}_{3}$ mixture). In each case, three different ice temperatures are shown: $10 \mathrm{~K}$ (dotted curves), $50 \mathrm{~K}$ (dashed curves), and $80 \mathrm{~K}$ (dot-dashed curves). As before, the comparisons are done by eye rather than by any formal fitting routine. The $\mathrm{H}_{2} \mathrm{O}: \mathrm{NH}_{3}$ ices at 10 and $50 \mathrm{~K}$ give the best match. The shape of the profile changes with increasing temperature, the feature becoming sharper in warmed (annealed) ices. This allows the possibility of a deeper feature in W33A while maintaining a reasonable fit to the short-wavelength wing. The existence of partially annealed ices toward W33A is supported by the analysis of other features, notably the $\mathrm{CO}_{2}$ bending mode (Gerakines et al. 1999; Boogert et al. 2000). Column density estimates based on the laboratory fits shown in Figures $3 c$ and $3 d$ lie in the range $(0.8-$ 1.8) $\times 10^{19} \mathrm{~cm}^{-2}$. Taking into consideration the level of agreement of each curve with the observational data, we deduce the most probable value to be $N\left(\mathrm{H}_{2} \mathrm{O}\right)=(1.2 \pm 0.3)$ $\times 10^{19} \mathrm{~cm}^{-2}$, consistent with the value deduced from the astronomical comparison above. The error reflects the fact that curves with a range of peak optical depths give acceptable fits to the short-wavelength profile. In any case, it appears that a large $\mathrm{H}_{2} \mathrm{O}$ ice column density $\left(>2 \times 10^{19}\right.$ $\mathrm{cm}^{-2}$ ) toward W33A is inconsistent with the profile of the stretching-mode feature for any of our adopted comparisons.

\subsection{Combination Mode}

The combination mode $\left(3 v_{L}\right.$ and/or $v_{2}+v_{L}$, where $L$ indicates libration) is the weakest $\mathrm{H}_{2} \mathrm{O}$ feature in the midinfrared region. It peaks at $4.5 \mu \mathrm{m}\left(2200 \mathrm{~cm}^{-1}\right)$ and extends from approximately 3.7 to $5 \mu \mathrm{m}$ (Hagen, Tielens, \& Greenberg 1981). This spectral region is illustrated in Figure 5. At 


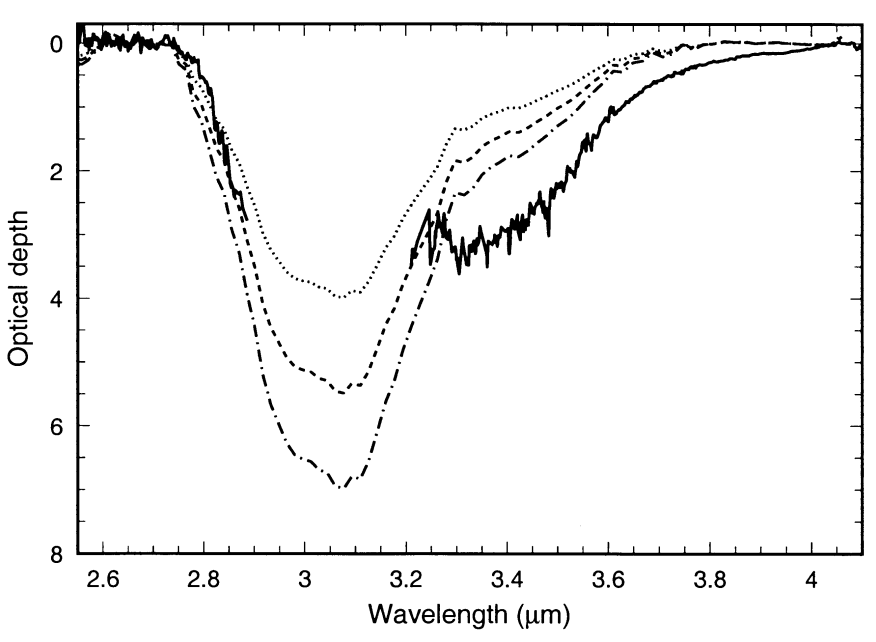

FIG. $3 a$

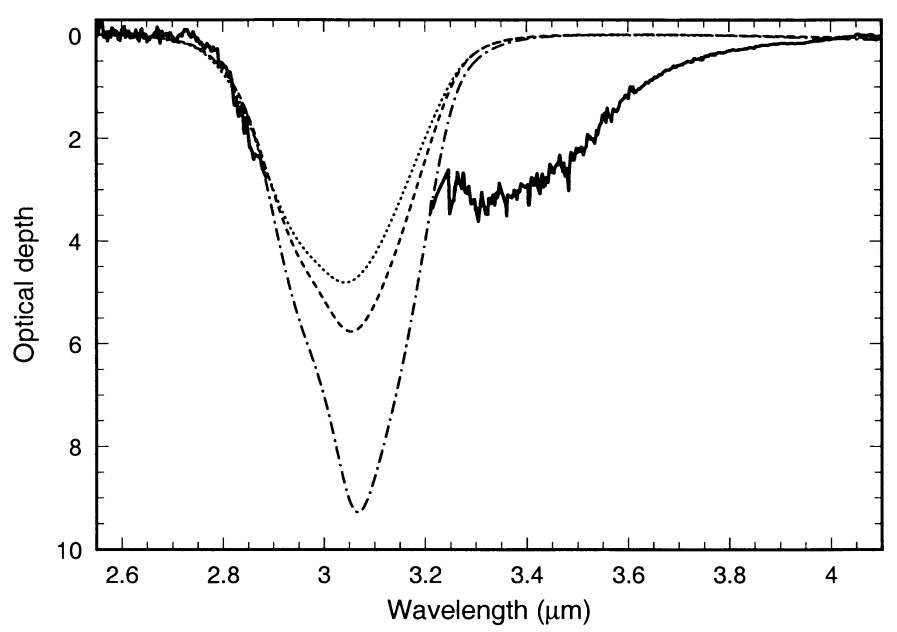

FIG. $3 c$

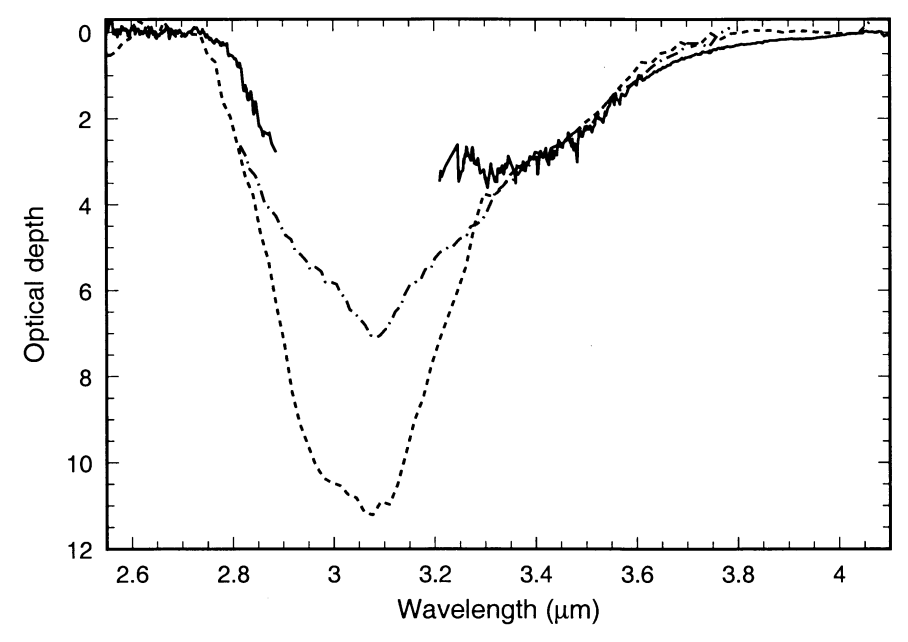

FIG. $3 b$

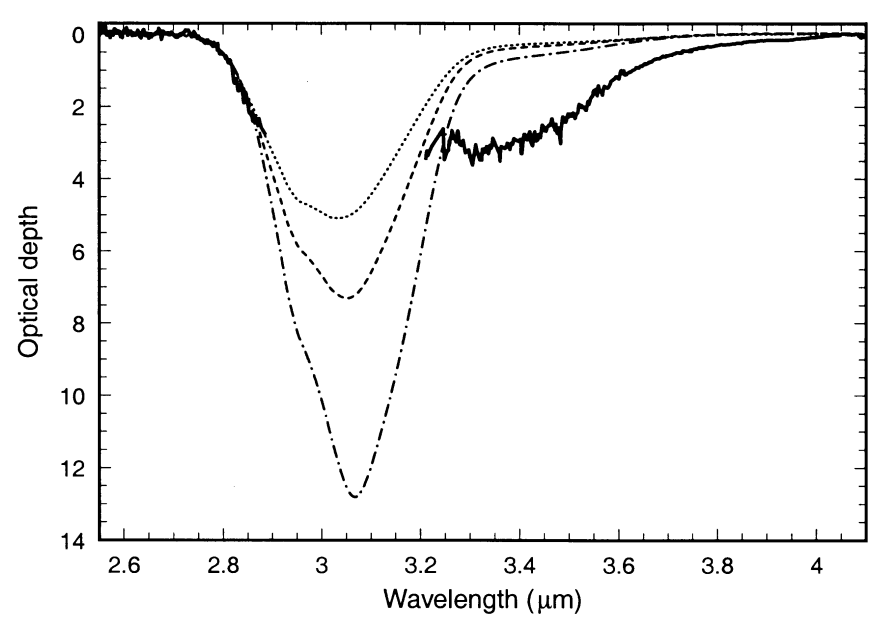

FIG. $3 d$

FIG. 3. - Comparisons of the observed $3 \mu \mathrm{m}$ ice feature in W33A with observational and laboratory profiles. The solid line is the observed spectrum of W33A in each case. (a) Comparison with the mean observed profile from SWS spectra of several YSOs (Fig. 4) for a representative range of normalizations. The peak $3 \mu \mathrm{m}$ optical depths of the dotted, dashed, and dot-dashed curves are 4.0, 5.5, and 7.0, respectively. (b) Comparisons with the mean observed profile (Fig. 4, dashed curve) and with the profile observed in Mon R2 IRS 3 alone (dot-dashed curve). In each case, the normalization is optimized for the 3.3-3.6 $\mu \mathrm{m}$ long-wavelength wing. (c) Comparison with laboratory profiles for pure $\mathrm{H}_{2} \mathrm{O}$ ice at three temperatures: $10 \mathrm{~K}$ (upper), $50 \mathrm{~K}$ (middle), and $80 \mathrm{~K}$ (lower). The laboratory spectra are scaled to match the short-wavelength wing of the W33A profile. (d) As (c), but for a 100:9 $\mathrm{H}_{2} \mathrm{O}: \mathrm{NH}_{3}$ mixture.

a column density of $N\left(\mathrm{H}_{2} \mathrm{O}\right) \sim 10^{19} \mathrm{~cm}^{-2}$, the peak optical depth of the combination mode is predicted to be $\sim 0.15$. A broad, shallow feature centered at $\sim 4.5 \mu \mathrm{m}$ with peak optical depth $\sim 0.1$ does, indeed, appear to underlie the much deeper ${ }^{12} \mathrm{CO}_{2},{ }^{13} \mathrm{CO}_{2}, \mathrm{CO}$, and $\mathrm{XCN}$ features. Also shown in Figure 5 is the profile of the combination mode in a laboratory ice: the $100: 9 \mathrm{H}_{2} \mathrm{O}: \mathrm{NH}_{3}$ mixture at $50 \mathrm{~K}$ was chosen for illustration. The observed spectrum was also compared with other laboratory mixtures (as in § 3.1) with similar results; however, given the shallowness and breadth of the combination mode, and the presence of strong blended features, it is not possible to discriminate decisively between different ice temperatures and compositions. Our conclusion is that the combination mode is detected in W33A with a central depth $\tau_{\max }=0.10 \pm 0.05$.

The $\mathrm{H}_{2} \mathrm{O}$ column implied by the strength of the combination mode was estimated, using band strength data from Gerakines et al. (1995), to be

$$
N\left(\mathrm{H}_{2} \mathrm{O}\right)=(0.7 \pm 0.4) \times 10^{19} \mathrm{~cm}^{-2} .
$$

The band strength is somewhat dependent on the composition and temperature of the ice, but the variation is small when compared to the final error, which is due primarily to uncertainty in continuum placement. This result is somewhat less than that obtained from the stretching mode (§3.1), but consistent within the estimated uncertainty.

\subsection{Bending Mode}

How can the $\mathrm{H}_{2} \mathrm{O}$ ice column densities deduced from the stretching and combination modes be reconciled with the substantially higher value implied by the bending mode? Like the stretching mode, the bending mode is blended owing to the superposition of features arising in other molecules thought to be present in the ices or in other grain constituents. These include features on both the short- and long-wavelength sides of the $6.0 \mu \mathrm{m}$ profile, i.e., at $5.83 \mu \mathrm{m}$ (attributed to $\mathrm{HCOOH}$ and $\mathrm{H}_{2} \mathrm{CO}$ ), $6.14 \mu \mathrm{m}\left(\mathrm{NH}_{3}\right)$, and 6.2 $\mu \mathrm{m}$ (aromatic compounds) (see Schutte et al. 1996a, 1998, 1999; Keane et al. 2000a). Although these blends might lead

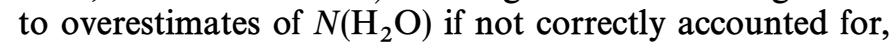




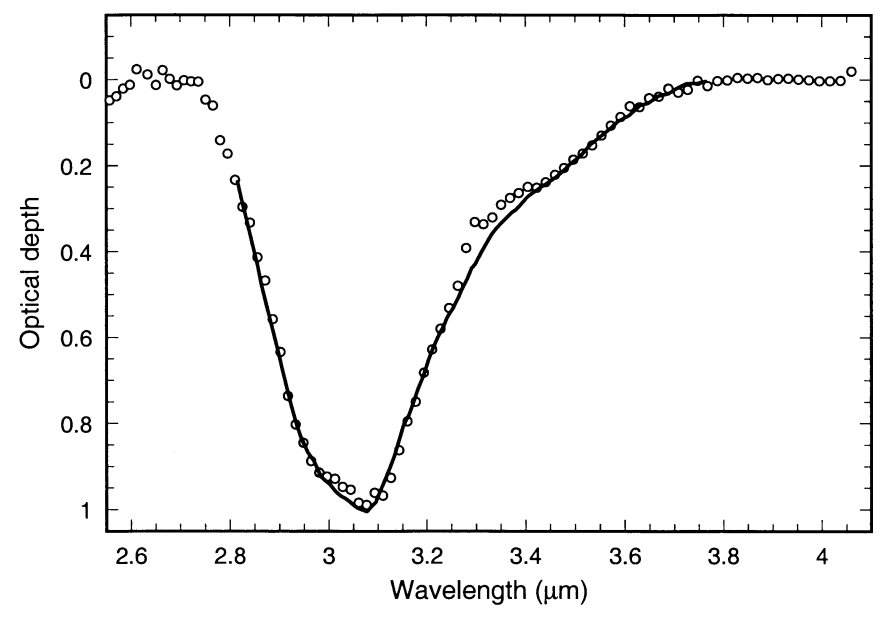

FIG. 4.-Mean observed profile of the $3 \mu \mathrm{m}$ ice absorption feature in several YSOs. Open circles: profile obtained from SWS spectra (mode S01, speed 4) of S140, NGC 7538 IRS 1, GL 490, and Elias 29. Solid curve: profile obtained from ground-based spectra (Smith et al. 1989) of BN, GL 961, GL 989, GL 2591, Mon R2 IRS 2, Mon R2 IRS 3, S255 IRS 1, and W3 IRS 5. Profiles were normalized to unit peak optical depth prior to averaging. The SWS data have been smoothed to match the resolution $(\sim 0.02$ $\mu \mathrm{m})$ of the ground-based data.

the effect appears to be insufficient to explain the discrepancy. A detailed analysis of high-resolution (S06 mode) spectra of W33A in the 5-8 $\mu \mathrm{m}$ spectral region (Keane et al. 2000 a) suggests a value of $N\left(\mathrm{H}_{2} \mathrm{O}\right) \approx 4.0 \times 10^{19} \mathrm{~cm}^{-2}$ from the bending mode. Thus, unless there is some unknown feature superposed on the $6 \mu \mathrm{m}$ feature of W33A (that is weak or absent in other protostars ${ }^{11}$ ), it does not seem possible to resolve this problem by spectroscopic considerations.

${ }^{11}$ Other sources studied by Keane et al. (2000a) show a tendency for $\mathrm{H}_{2} \mathrm{O}$ ice column densities from the bending mode to be somewhat greater than those from the stretching mode, but W33A is by far the most extreme case.

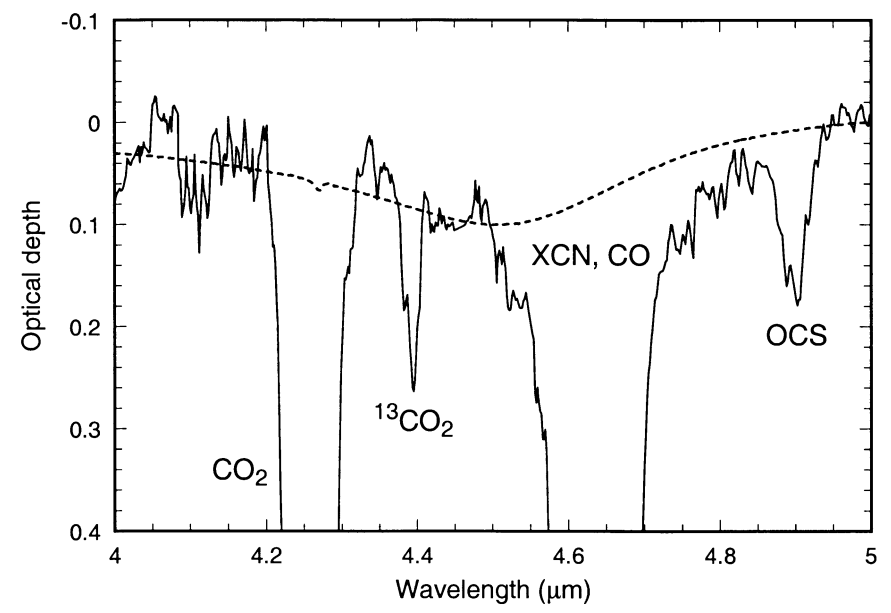

FIG. 5.-Optical depth spectrum of W33A from 4 to $5 \mu \mathrm{m}$. Deep features centered at 4.27, 4.39, 4.62, and $4.90 \mu \mathrm{m}$ are identified with $\mathrm{CO}_{2}$, ${ }^{13} \mathrm{CO}_{2}, \mathrm{XCN} / \mathrm{CO}$, and OCS, respectively. The dashed curve is a laboratory spectrum of $\mathrm{H}_{2} \mathrm{O}: \mathrm{NH}_{3}(100: 9)$ ice at $50 \mathrm{~K}$, scaled to the most probable depth of the broad, shallow $\mathrm{H}_{2} \mathrm{O}$ ice combination mode feature centered near $4.5 \mu \mathrm{m}$ in the observed spectrum $(\S 3.2)$. This spectrum is also used to place limits on the abundance of nitriles absorbing at 4.42-4.57 $\mu \mathrm{m}(\S 5)$.
An alternative possibility is that an unusual source structure might be responsible for the anomaly in W33A. For example, the $3 \mu \mathrm{m}$ flux might include a contribution from scattered radiation (Brooke, Sellgren, \& Smith 1996); if the scattered component traverses a path of lower optical depth than that in the direct line of sight to the source, the apparent depth of the $3 \mu \mathrm{m}$ feature will be reduced. Scattering is less at longer wavelengths and could be negligible at $6 \mu \mathrm{m}$, in which case the bending-mode feature should measure the true column density. However, the fact that the combination mode yields a column density closer to the stretching-mode result than to the bending-mode result is an argument against this hypothesis. The optical depth of the combination mode should be $\sim 0.5$ if the bending-mode value of $N\left(\mathrm{H}_{2} \mathrm{O}\right)$ is assumed, a value clearly inconsistent with the observed spectrum (Fig. 5).

\subsection{Comparison with $\mathrm{CO}_{2}$}

As a further constraint, we consider the correlation of $\mathrm{H}_{2} \mathrm{O}$ and $\mathrm{CO}_{2}$ column densities in the ices toward various objects. A previous study has shown that a very tight correlation exists between $N\left(\mathrm{H}_{2} \mathrm{O}\right)$ and $N\left(\mathrm{CO}_{2}\right)$ (see Fig. 12 in Gerakines et al. 1999). The ratio $N\left(\mathrm{CO}_{2}\right) / N\left(\mathrm{H}_{2} \mathrm{O}\right)$ is typically $\sim 17 \%$, with an extreme range of $10 \%-23 \%$ for a sample of 15 sources. The sample includes lines of sight to the Galactic center and to the Taurus field star Elias 16, as well as to various young stellar objects, suggesting that the $\mathrm{CO}_{2}$ concentration in interstellar ices is robust and insensitive to differing physical conditions. Toward W33A, we have $N\left(\mathrm{CO}_{2}\right) \approx 14.5 \times 10^{17} \mathrm{~cm}^{-2}$, measured from the bending mode of $\mathrm{CO}_{2}$ at $15 \mu \mathrm{m}$ (the stretching mode at 4.27 $\mu \mathrm{m}$ is saturated; Gerakines et al. 1999). As an independent check, the unsaturated ${ }^{13} \mathrm{CO}_{2}$ stretching mode at $4.39 \mu \mathrm{m}$ yields $N\left(\mathrm{CO}_{2}\right) \approx 14.0 \times 10^{17} \mathrm{~cm}^{-2}$ if we assume a typical value of 50 for the ${ }^{12} \mathrm{C} /{ }^{13} \mathrm{C}$ ratio in $\mathrm{CO}_{2}$ toward $\mathrm{W} 33 \mathrm{~A}$ (Boogert et al. 2000), in good agreement with the bending mode result. The $\mathrm{CO}_{2}$ concentration is thus $\sim 13 \%$ using $N\left(\mathrm{H}_{2} \mathrm{O}\right)$ from the stretching mode, but only $\sim 3 \%-4 \%$ using $N\left(\mathrm{H}_{2} \mathrm{O}\right)$ from the bending mode. If the latter value were correct, W33A would be unique among sources so far studied; rather, we take this result as indirect support for the lower value of $N\left(\mathrm{H}_{2} \mathrm{O}\right) \sim 1 \times 10^{19} \mathrm{~cm}^{-2}$. It should also be noted that because $N\left(\mathrm{CO}_{2}\right)$ is measured from a feature at $15 \mu \mathrm{m}$, i.e., at a wavelength longward of the $6 \mu \mathrm{m}$ feature, it is highly implausible that geometrical effects can explain the anomaly whilst simultaneously satisfying the $\mathrm{CO}_{2} / \mathrm{H}_{2} \mathrm{O}$ constraint.

\subsection{Summary}

On the basis of the various results and arguments presented in this section, we conclude that

$$
N\left(\mathrm{H}_{2} \mathrm{O}\right)=(1.1 \pm 0.3) \times 10^{19} \mathrm{~cm}^{-2}
$$

is the most probable value of the $\mathrm{H}_{2} \mathrm{O}$ ice column density toward W33A. We adopt this value in the following section. This result is consistent with all known observational constraints, with the exception of the bending-mode feature at $6.0 \mu \mathrm{m}$. The reason for this discrepancy remains puzzling.

\section{DETECTION OF AMMONIA ICE}

Until recently, the $\mathrm{C} \equiv \mathrm{N}$ stretching mode at $4.62 \mu \mathrm{m}$ (Pendleton et al. 1999 and references therein) provided the only direct evidence for the presence of nitrogen-bearing species in interstellar ices. Among other likely candidates, $\mathrm{N}_{2}$ is infrared-inactive (Ehrenfreund \& van Dishoeck 1998), 
and $\mathrm{NH}_{3}$ has proved elusive because its principal vibrational modes overlap strong features of $\mathrm{H}_{2} \mathrm{O}$ ice and silicates (see Smith et al. 1989; Whittet et al. 1996; Lacy et al. 1998; Keane et al. 2000a). However, recent detections of $\mathrm{NH}_{3}$ have been reported, based on observations of the inversion mode near $9.0 \mu \mathrm{m}\left(1110 \mathrm{~cm}^{-1}\right)$ toward NGC 7538 IRS 9 (Lacy et al. 1998), and the stretching mode at $2.95 \mu \mathrm{m}$ $\left(3390 \mathrm{~cm}^{-1}\right)$ toward the Galactic center (Chiar et al. 2000). We report here, for the first time, detection of $\mathrm{NH}_{3}$ in ices toward W33A. This was accomplished by careful analysis of the silicate profile in the region of the inversion feature, analogous to the study of NGC 7538 IRS 9 by Lacy et al. (1998).

Figure $6 a$ shows the $8-11 \mu \mathrm{m}$ flux spectrum of W33A. The profile exhibits a change in slope at $\sim 8.5 \mu \mathrm{m}$ (the approximate cut-on point of the $\mathrm{NH}_{3}$ feature in NGC 7538 IRS 9) and an inflection near $9.5 \mu \mathrm{m}$. This is, in fact, consistent with the presence of two adjacent absorption features, approximately $8.5-9.5 \mu \mathrm{m}$ and $9.5-10.0 \mu \mathrm{m}$ in extent, the first of which we attribute to $\mathrm{NH}_{3}$, the second to the $\mathrm{CO}$ stretching mode in $\mathrm{CH}_{3} \mathrm{OH}$ (Schutte, Tielens, \& Stanford 1991; Skinner et al. 1992). A local continuum for the two features was determined by fitting a polynomial of fifth order to the $\log$ (flux) spectrum in the ranges 8.0-8.5, 9.459.55, and 10.05-11.0 $\mu \mathrm{m}$. The fitted curve is shown in Figure $6 a$, and the resulting optical depth spectrum is presented in Figure $6 b$. Also shown in Figure $6 b$ are laboratory spectra for (1) the $\mathrm{H}_{2} \mathrm{O}: \mathrm{NH}_{3}=100: 9$ ice mixture at $50 \mathrm{~K}$ previously discussed (§3) and (2) a $\mathrm{H}_{2} \mathrm{O}: \mathrm{CH}_{3} \mathrm{OH}: \mathrm{CO}_{2}=$ 1.25:1.2:1.0 ice mixture at $70 \mathrm{~K}$; these were scaled to match the depths of the 9.0 and $9.8 \mu \mathrm{m}$ features, respectively. The observed spectrum is very noisy longward of $9.0 \mu \mathrm{m}$, owing to low flux levels in the depths of the silicate feature; given the quality of the data, the precise temperature and composition of the laboratory spectra selected are not critical. From inspection of Figure $6 b$, the $9.8 \mu \mathrm{m}$ feature in $\mathrm{W} 33 \mathrm{~A}$ is seen to be consistent with $\mathrm{H}_{2} \mathrm{O}: \mathrm{CH}_{3} \mathrm{OH}: \mathrm{CO}_{2}$ ice, while the $9.0 \mu \mathrm{m}$ feature is well matched by the spectrum of $\mathrm{H}_{2} \mathrm{O}: \mathrm{NH}_{3}$ ice on the short-wavelength side. The deviation between observed and laboratory spectra in the 9.0-9.4 $\mu \mathrm{m}$

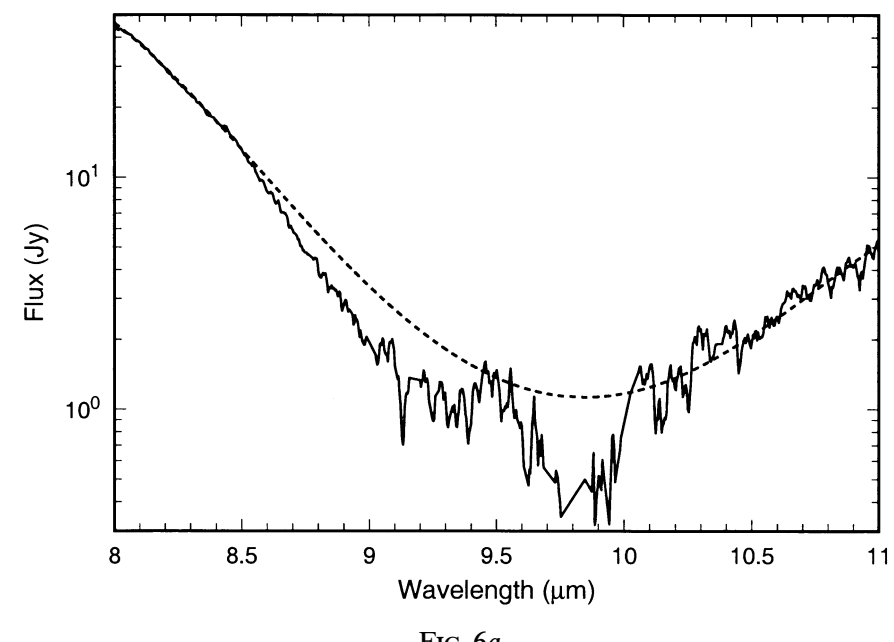

FIG. $6 a$ region is most likely due to noise in the former, although we cannot exclude the possibility of additional blended absorption features in W33A over this spectral range.

To estimate the column density of $\mathrm{NH}_{3}$ in ices toward W33A, we use the laboratory curve (Fig. $6 b$ ) as a guide to the long-wavelength profile of the $9.0 \mu \mathrm{m}$ feature, ignoring the noisy 9.0-9.4 $\mu \mathrm{m}$ segment in the observed spectrum. The width (FWHM) of the laboratory profile is $\sim 50 \mathrm{~cm}^{-1}$, and we estimate the central optical depth of the observed feature to be $0.45 \pm 0.10$. Using band strength data $\left(A \approx 1.3 \times 10^{-17} \mathrm{~cm}\right.$ per molecule) from Kerkhof, Schutte, \& Ehrenfreund (1999), the column density is

$$
N\left(\mathrm{NH}_{3}\right)=(1.7 \pm 0.4) \times 10^{18} \mathrm{~cm}^{-2} \text {. }
$$

This result implies an $\mathrm{NH}_{3}$ concentration relative to $\mathrm{H}_{2} \mathrm{O}$ ice (§ 3.5$)$ of $\sim 15 \%$ toward W33A. For comparison, the $\mathrm{NH}_{3}$ concentration toward NGC 7538 IRS 9 was estimated to be $\sim 10 \%$ by Lacy et al. (1998) - a value that increases to $\sim 13 \%$ if the new band strength data from Kerkhof et al. (1999) are adopted. $\mathrm{NH}_{3}$ concentrations of $10 \%-15 \%$ in interstellar ices toward YSOs seem reasonable and not seriously conflicted with constraints of $\lesssim 10 \%$ placed by the $\mathrm{N}-\mathrm{H}$ stretching and deformation modes at 2.95 and 6.14 $\mu \mathrm{m}$, respectively (e.g., Whittet et al. 1996; Keane et al. 2000a). Appreciably higher values $(20 \%-30 \%)$ have been reported for the line of sight to the Galactic center (Chiar et al. 2000).

The $9.8 \mu \mathrm{m} \mathrm{CH}_{3} \mathrm{OH}$ feature has an estimated central depth $0.9 \pm 0.2$ and width (FWHM) $\sim 30 \mathrm{~cm}^{-1}$. Using band strength data from Schutte et al. (1991), we estimate the column density to be $N\left(\mathrm{CH}_{3} \mathrm{OH}\right)=(1.5 \pm 0.4) \times 10^{18}$ $\mathrm{cm}^{-2}$. This result may be compared with values of $N\left(\mathrm{CH}_{3} \mathrm{OH}\right) \approx(1.7-2.1) \times 10^{18} \mathrm{~cm}^{-2}$ estimated from the $\mathrm{CH}$ stretching and combination modes (Chiar, Adamson, \& Whittet 1996; Dartois et al. 1999). The degree of consistency gives us confidence in our method for exhuming these features from the silicate profile. $\mathrm{CH}_{3} \mathrm{OH}$ also possesses a weak rocking mode of width $\sim 15 \mathrm{~cm}^{-1}$ near $8.9-9.0 \mu \mathrm{m}$, and a peak optical depth of $\sim 0.1$ is predicted by the column density estimated from the $\mathrm{CO}$ stretching mode; the spec-

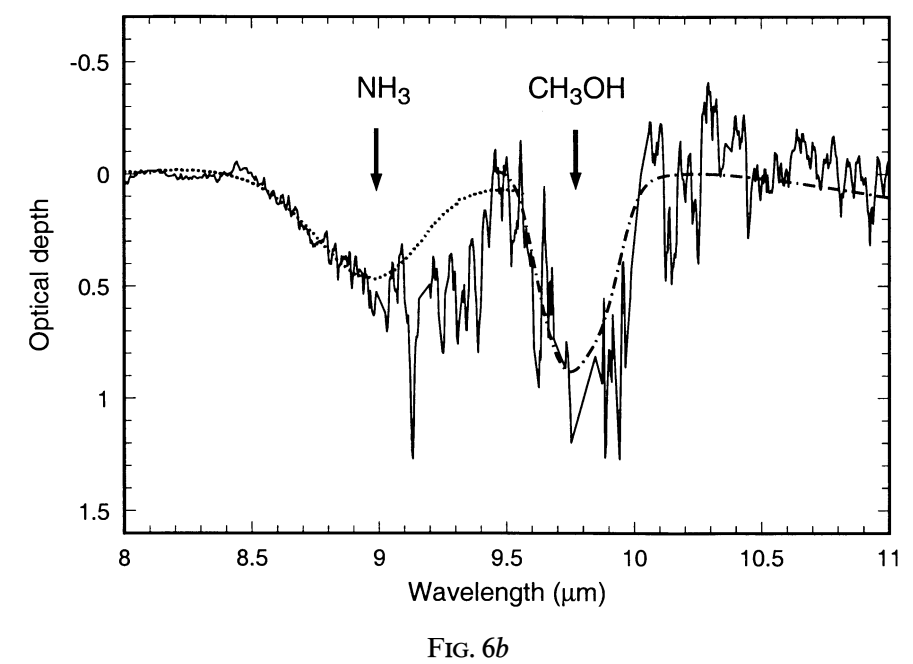

FIG. 6.- Spectra of W33A in the vicinity of the $\mathrm{NH}_{3}$ (inversion mode) and $\mathrm{CH}_{3} \mathrm{OH}$ (CO-stretching mode) absorptions centered near 9.0 and $9.8 \mu$ m, respectively. (a) Flux spectrum, showing a fifth-order polynomial fit (dashed curve) used to extract the features from the silicate profile. (b) Optical depth spectrum over the same spectral range, obtained using the continuum shown in (a). The positions of the $\mathrm{NH}_{3}$ and $\mathrm{CH}_{3} \mathrm{OH}$ features are indicated. Also shown are laboratory spectra for $\mathrm{H}_{2} \mathrm{O}: \mathrm{NH}_{3}(100: 9)$ ice at $50 \mathrm{~K}$ (dotted curve), and $\mathrm{H}_{2} \mathrm{O}: \mathrm{CH}_{3} \mathrm{OH}: \mathrm{CO}_{2}(1.25: 1.2: 1.0)$ ice at $70 \mathrm{~K}$ (dot-dashed curve), scaled to match the profiles of the 9.0 and $9.8 \mu \mathrm{m}$ features, respectively. 
trum in Figure $6 b$ is consistent with the presence of such a weak feature near the center of the $\mathrm{NH}_{3}$ band.

\section{NITRILES}

Prime candidates for the $4.62 \mu \mathrm{m}$ " $\mathrm{XCN}$ " feature include isonitriles $(\mathrm{X}-\mathrm{N} \equiv \mathrm{C})$ and cyanates $(\mathrm{X}-\mathrm{O}-\mathrm{C} \equiv \mathrm{N}$ ) (see Pendleton et al. 1999 for a recent review). If isonitriles are, indeed, present in interstellar ices, their abundances might reasonably be expected to be no greater than those of the corresponding nitriles $(\mathrm{X}-\mathrm{C} \equiv \mathrm{N})$, as the latter are generally more stable (Pendleton et al. 1999). The gas-phase interstellar nitrile/isonitrile abundance ratio varies with physical conditions: in cold, dark clouds, it is close to unity (Hirota et al. 1998), increasing to values as high as $\sim 10-300$ (owing to selective destruction of isonitriles) in the environs of luminous YSOs (Goldsmith et al. 1986; Cernicharo et al. 1988; Kawaguchi et al. 1992; Schilke et al. 1992). The $\mathrm{C} \equiv \mathrm{N}$ stretching feature in solid-phase nitriles typically falls at significantly shorter wavelength $(4.35-4.55 \mu \mathrm{m})$ compared with isonitriles (although some nitriles that form strong complexes with $\mathrm{H}_{2} \mathrm{O}$ also absorb near $4.6 \mu \mathrm{m}$; Bernstein, Sandford, \& Allamandola 1997). Thus, nitriles that might exist in interstellar ices are generally inaccessible to groundbased observation owing to strong $4.1-4.5 \mu \mathrm{m}$ telluric absorption. With the availability of ISO SWS data for W33A (the source with the strongest known $4.62 \mu \mathrm{m}$ feature), it is timely to place quantitative limits on the abundance of nitriles in the ices.

Laboratory spectra covering the $\mathrm{C} \equiv \mathrm{N}$ stretch region for several nitriles frozen in an $\mathrm{H}_{2} \mathrm{O}$ ice matrix are presented by Bernstein et al. (1997; their Fig. 4). Absorption features are typically $20 \mathrm{~cm}^{-1}(0.04 \mu \mathrm{m})$ in width, with peak position ranging from 4.42 to $4.57 \mu \mathrm{m}$ (the majority lying between 4.42 and $4.50 \mu \mathrm{m}$ ). If a variety of nitriles are present in interstellar ices, a somewhat broader composite feature centered at $\sim 4.47 \mu \mathrm{m}$ should be seen. We have examined both mode S01 (Fig. 5) and higher resolution mode S06 data in the $4.40-4.57 \mu \mathrm{m}$ spectral region, with consistent results. There is some evidence for weak structure in the 4.50-4.57 $\mu \mathrm{m}$ region, on the shoulder of the deep $4.62 \mu \mathrm{m}$ feature, that might be attributed to nitrile absorption. However, no features are seen in the $4.42-4.50 \mu \mathrm{m}$ region, where the majority of nitriles have their $\mathrm{CN}$ signatures. We estimate a conservative upper limit of 0.05 on the optical depth of any nitrile feature present (a more stringent limit of 0.03 is obtained if only the $4.42-4.50 \mu \mathrm{m}$ region is considered). These values may be compared with $\tau_{\max } \approx 1.4$ in the XCN feature at $4.62 \mu \mathrm{m}$. The band strength of the $\mathrm{C} \equiv \mathrm{N}$ stretch for a typical nitrile in $\mathrm{H}_{2} \mathrm{O}$ ice is $\sim 1.0 \times 10^{-17} \mathrm{~cm}$ per molecule (Bernstein et al. 1997), and hence, the column density of nitriles toward W33A is

$$
N \text { (nitriles) }<1.0 \times 10^{17} \mathrm{~cm}^{-2}
$$

using the more conservative limit on the optical depth. For comparison, assignment of the $4.62 \mu \mathrm{m}$ feature to isonitriles (which have band strength typically a factor $\sim 3$ higher; Bernstein et al. 1997) leads to a column density an order of magnitude above the limit for nitriles, i.e. $N$ (nitrile)/ $N$ (isonitrile) $<0.1$. Such a low abundance of nitriles relative to isonitriles seems highly implausible and argues against assignment of the XCN feature to isonitriles.

Cyanate appears to be the class of XCN absorber most consistent with existing spectroscopic constraints (see Schutte \& Greenberg 1997, Pendleton et al. 1999, and
Palumbo et al. 2000 for further discussion). In the following section (Tables 1 and 2), we adopt a band strength of $1.0 \times 10^{-16} \mathrm{~cm}$ per molecule for the XCN feature, appropriate to the cyanate ion $\mathrm{OCN}^{-}$(Keane et al. 2000b).

\section{AN INVENTORY OF SOLID-STATE MOLECULAR ABUNDANCES}

Table 1 lists column densities for all species identified in the spectrum of W33A. In general, we adopt values presented in previous literature where available, either from ISO SWS (mode S06) spectra or ground-based observations of equivalent quality and spectral resolution. A few identifications are tentative (see the notes to Table 1). For example, $\mathrm{HCOO}^{-}$and $\mathrm{CH}_{3} \mathrm{HCO}$ are both candidates for assignment of the weak feature at $7.41 \mu \mathrm{m}$ (Schutte et al. 1999).

Table 2 compares results for W33A and other wellstudied infrared sources displaying interstellar ice features in their spectra. The sources were selected to represent a range of environments, including different levels of thermal and energetic processing. They include the field star Elias 16 (situated behind the Taurus dark cloud), the Galactic center source Sgr A* (obscured by a combination of diffuse and dense cloud material), and three embedded YSOs (NGC

TABLE 1

Column Densities of Molecular ICes DETECTED TOWARD W33A

\begin{tabular}{|c|c|c|}
\hline Species & $\begin{array}{c}N \\
\left(10^{17} \mathrm{~cm}^{-2}\right)\end{array}$ & Notes \\
\hline $\mathrm{H}_{2} \mathrm{O} \ldots \ldots \ldots \ldots \ldots$ & 110 & 1 \\
\hline HDO ................ & 0.3 & 2 \\
\hline $\mathrm{CO}$ (total) ............ & 8.9 & 3 \\
\hline $\mathrm{CO}$ (polar) ............ & 6.6 & 3 \\
\hline $\mathrm{CO}$ (nonpolar) ....... & 2.3 & 3 \\
\hline $\mathrm{CO}_{2}$ (total) $\ldots \ldots \ldots \ldots$ & 14.5 & 4 \\
\hline $\mathrm{CO}_{2}$ (polar) ......... & 12.3 & 4 \\
\hline $\mathrm{CO}_{2}$ (nonpolar)...... & 2.2 & 4 \\
\hline${ }^{13} \mathrm{CO}_{2} \ldots \ldots \ldots \ldots \ldots$ & 0.27 & 5 \\
\hline $\mathrm{CH}_{4} \ldots \ldots \ldots \ldots \ldots \ldots$ & 1.7 & 6 \\
\hline $\mathrm{CH}_{3} \mathrm{OH} \ldots \ldots \ldots \ldots$ & 19.5 & 7 \\
\hline $\mathrm{H}_{2} \mathrm{CO} \ldots \ldots \ldots \ldots \ldots$ & 7.1 & 8 \\
\hline НСООН ............ & 7.8 & 9 \\
\hline $\mathrm{HCOO}^{-} \ldots \ldots \ldots \ldots$ & 0.9 & 10 \\
\hline $\mathrm{CH}_{3} \mathrm{HCO} \ldots \ldots \ldots \ldots$ & 10.8 & 10 \\
\hline OCS …............... & 0.2 & 11 \\
\hline $\mathrm{NH}_{3} \ldots \ldots \ldots \ldots \ldots \ldots$ & 17 & 12 \\
\hline $\mathrm{XCN} \ldots \ldots \ldots \ldots \ldots$ & 3.8 & 13 \\
\hline
\end{tabular}

NoTes.-(1) This paper, § 3. (2) Based on a tentative detection of the $\mathrm{O}-\mathrm{D}$ stretching mode at $4.1 \mu \mathrm{m}$ by Teixeira et al. 1999. (3) Chiar et al. 1998. (4) Based on the bending mode; Gerakines et al. 1999. (5) Boogert et al. 1999. (6) Boogert et al. 1996, 1998. (7) Mean of results for the $\mathrm{C}-\mathrm{H}$ stretch and combination modes; Chiar et al. 1996; Dartois et al. 1999. (8) Based on estimated contribution of the $\mathrm{C}=\mathrm{O}$ stretching mode to the observed $6.0 \mu \mathrm{m}$ feature and consistent with upper limits on absorption in the $\mathrm{C}-\mathrm{H}$ stretch region near 3.5 $\mu \mathrm{m}$; Keane et al. 2000a; Brooke et al. 1999. (9) Based on assignment of the $7.24 \mu \mathrm{m}$ feature; Schutte et al. 1999. (10) Tentative, based on assignment of the $7.41 \mu \mathrm{m}$ feature; Schutte et al. 1999. (11) Palumbo et al. 1995. (12) This paper, § 4. (13) Notional, assuming a band strength for the $\mathrm{C} \equiv \mathrm{N}$ stretching mode at $4.62 \mu \mathrm{m}$ appropriate to the $\mathrm{OCN}^{-}$ion (§ 5); observational data from Chiar et al. 1998. 
TABLE 2

ICE Abundances toward INFRARED SOURCES AND COMETs ${ }^{\mathrm{a}}$

\begin{tabular}{|c|c|c|c|c|c|c|c|}
\hline Species & Elias $16^{b}$ & NGC 7538 IRS $9^{c}$ & GL 7009S & $\mathrm{W} 33 \mathrm{~A}^{\mathrm{e}}$ & GL $2136^{\mathrm{f}}$ & $\operatorname{Sgr} A^{* g}$ & Comets $^{\mathrm{h}}$ \\
\hline $\mathrm{H}_{2} \mathrm{O} \ldots \ldots \ldots \ldots \ldots$ & 100 & 100 & 100 & 100 & 100 & 100 & 100 \\
\hline $\mathrm{CO}($ total $) \ldots \ldots \ldots \ldots$ & 25 & 16 & 15 & 8 & 2 & $<12$ & $5-30$ \\
\hline $\mathrm{CO}$ (polar) ........... & 3 & 2 & $\ldots$ & 6 & 2 & $\ldots$ & $\ldots$ \\
\hline $\mathrm{CO}$ (nonpolar) ....... & 22 & 14 & $\ldots$ & 2 & $\ldots$ & $\ldots$ & $\ldots$ \\
\hline $\mathrm{CO}_{2}$ (total) ......... & 18 & 22 & 21 & 13 & 16 & 14 & $3-20$ \\
\hline $\mathrm{CO}_{2}$ (polar) .......... & 18 & 14 & $\ldots$ & 11 & 13 & 14 & $\ldots$ \\
\hline $\mathrm{CO}_{2}$ (nonpolar)...... & $<1$ & 8 & $\ldots$ & 2 & 3 & $<1$ & $\ldots$ \\
\hline $\mathrm{CH}_{4} \ldots \ldots \ldots \ldots \ldots \ldots$ & $\ldots$ & 2 & 4 & 1.5 & $\ldots$ & 2 & 1 \\
\hline $\mathrm{CH}_{3} \mathrm{OH} \ldots \ldots \ldots \ldots$ & $<3$ & 5 & 30 & 18 & 6 & $<4$ & $0.3-5$ \\
\hline $\mathrm{H}_{2} \mathrm{CO} \ldots \ldots \ldots \ldots \ldots$ & $\ldots$ & 4 & 3 & 6 & 3 & $<3$ & $0.2-1$ \\
\hline $\mathrm{HCOOH}, \ldots . . . . . .$. & $\ldots$ & 3 & $\ldots$ & 7 & $\ldots$ & 3 & 0.05 \\
\hline OCS $\ldots \ldots \ldots \ldots \ldots \ldots$ & $<0.2$ & $\ldots$ & 0.2 & 0.2 & $\ldots$ & $\ldots$ & 0.5 \\
\hline $\mathrm{NH}_{3} \ldots \ldots \ldots \ldots \ldots$ & $\lesssim 9$ & 13 & $\ldots$ & 15 & $\ldots$ & $20-30$ & $0.1-1.8$ \\
\hline $\mathrm{XCN}^{\mathrm{i}} \ldots \ldots \ldots \ldots \ldots$ & $<0.5$ & 1 & 1.5 & 3.5 & 0.3 & $\ldots$ & $0.01-0.4$ \\
\hline
\end{tabular}

${ }^{\text {a }}$ All results are expressed as a percentage of the adopted $N\left(\mathrm{H}_{2} \mathrm{O}\right)$ column density (see notes). Only species with detections in two or more sources are included. Infrared sources are listed in a probable sequence of increasing thermal processing of the ices from left to right, as suggested by the (nonpolar) solid $\mathrm{CO}$ abundance.

${ }^{b} \mathrm{~N}\left(\mathrm{H}_{2} \mathrm{O}\right)=2.5 \times 10^{18} \mathrm{~cm}^{-2}$, estimated from the stretching mode. Data from Chiar et al. 1995, 1996; Gerakines et al. 1999; Palumbo, Geballe, \& Tielens 1997; Tegler et al. 1995; van de Bult, Greenberg, \& Whittet 1985; Whittet et al. 1998.

${ }^{c} N\left(\mathrm{H}_{2} \mathrm{O}\right)=7.5 \times 10^{18} \mathrm{~cm}^{-2}$, averaged from stretching- and bending-mode values. $\mathrm{NH}_{3}$ abundance from Lacy et al. 1998, recalculated using new band strength data from Kerkhof et al. 1999. Other results from Allamandola et al. 1992; Boogert et al. 1998; Chiar et al. 1996, 1998; Gerakines et al. 1999; Keane et al. 2000a; Pendleton et al. 1999; Schutte et al. 1996a.

${ }^{d} \mathrm{~N}\left(\mathrm{H}_{2} \mathrm{O}\right)=1.2 \times 10^{19} \mathrm{~cm}^{-2}$, estimated from the bending mode. Data from Dartois et al. 1999; d'Hendecourt et al. 1996, 1998.

e See Table 1.

${ }^{\text {f }} \mathrm{N}\left(\mathrm{H}_{2} \mathrm{O}\right)=5.0 \times 10^{18} \mathrm{~cm}^{-2}$, averaged from stretching- and bending-mode values. Data from Brooke et al. 1999; Chiar et al. 1996; Gerakines et al. 1999; Keane et al. 2000a; Pendleton et al. 1999; Schutte et al. 1996b; Skinner et al. 1992 ; Tielens et al. 1991.

${ }^{\mathrm{g}} \mathrm{N}\left(\mathrm{H}_{2} \mathrm{O}\right)=1.25 \times 10^{18} \mathrm{~cm}^{-2}$, estimated from the stretching mode. Data from Gerakines et al. 1999 and Chiar et al. 2000 .

${ }^{\text {h }}$ Average values; Langer et al. 2000; Hudson \& Moore 1999; Cottin, Gazeau, \& Raulin 1999; Bird et al. 1997; and references therein.

${ }^{\mathrm{i}} \mathrm{XCN}$ column densities were calculated assuming a band strength for the $\mathrm{C} \equiv \mathrm{N}$ stretching mode appropriate to the $\mathrm{OCN}^{-}$ ion (Keane et al. 2000b; see $\S 5$ ).

7538 IRS 9, GL 7009S, and GL 2136). Values inferred for cometary ices are also given for comparison. Molecular abundances of the various species listed in Table 2 are expressed as a percentage of the adopted $N\left(\mathrm{H}_{2} \mathrm{O}\right)$ column density toward each source. The first five sources are ordered from left to right in a probable sequence of increasing thermal processing of the ices, as indicated by the abundance of $\mathrm{CO}$, the most volatile species represented. Elias 16 is believed to sample cold, quiescent material undisturbed by local star formation activity (e.g., Whittet et al. 1998 and references therein), whereas ices in the vicinity of YSOs may be subject to varying degrees of heating and/or energetic processing (e.g., van Dishoeck \& Blake 1998). In interpreting Table 2, it should be noted that thermal and energetic processing in an interstellar cloud are not necessarily coincident in space and time. Ices may be heated by infrared radiation while remaining shielded from more energetic photons; conversely, in different circumstances, they may be subject to ultraviolet irradiation yet experience little heating.

Some notable features of the results in Table 2 are now discussed. The $\mathrm{CO}_{2}$ abundance remains remarkably constant over a range of environments, as has been noted before (Gerakines et al. 1999; see $\S 3.4$ ), suggesting that the primary route(s) to its formation are robust and not strongly dependent on environment (Whittet et al. 1998). The $\mathrm{CH}_{3} \mathrm{OH}$ abundance is, in contrast, highly variable. Dartois et al. (1999) have noted $\mathrm{CH}_{3} \mathrm{OH}$ as the second most abundant ice species (after $\mathrm{H}_{2} \mathrm{O}$ ) toward the high-mass protostars GL 7009S and W33A, a result with which we concur; however, in the majority of lines of sight studied to date, $\mathrm{CH}_{3} \mathrm{OH}$ is less abundant than $\mathrm{CO}_{2}$ (Gerakines et al. 1999). If the sequence of sources in Table 2 is meaningful, then the $\mathrm{CH}_{3} \mathrm{OH}$ abundance appears to peak at intermediate levels of (thermal) processing. Interestingly, the two sources with the highest $\mathrm{CH}_{3} \mathrm{OH}$ abundances also have the highest notional XCN abundances. Based on its laboratory production and the environments in which it is observed, XCN is generally assumed to be the product of energetic processing of $\mathrm{NH}_{3}$-bearing ices (e.g., Pendleton et al. 1999), whereas $\mathrm{CH}_{3} \mathrm{OH}$ is thought to form by sequential $\mathrm{CO}$ hydrogenation reactions $\left(\mathrm{CO} \rightarrow \mathrm{HCO} \rightarrow \mathrm{H}_{2} \mathrm{CO} \rightarrow\right.$ $\mathrm{CH}_{2} \mathrm{OH} \rightarrow \mathrm{CH}_{3} \mathrm{OH}$ ) on grain surfaces (Tielens \& Charnley 1997). As some steps in this sequence possess activation energies, it may indeed be the case that efficient $\mathrm{CH}_{3} \mathrm{OH}$ production occurs only when ices are heated or subject to photolysis or ion bombardment (see Hudson \& Moore 1999 for discussion of relevant laboratory analog experiments). The fact that both $\mathrm{CH}_{3} \mathrm{OH}$ and XCN abundances are enhanced in protostellar regions provides support for the hypothesis that $\mathrm{CH}_{3} \mathrm{OH}$, like $\mathrm{XCN}$, is the product of local energetic or thermal processing.

In contrast to $\mathrm{CH}_{3} \mathrm{OH}, \mathrm{CH}_{4}$ has similar abundance in all sources for which data are available (NGC 7538 IRS 9, GL 7009S, W33A, and Sgr A*). This suggests that radiative processing is not an important factor in its formation, which presumably proceeds via surface hydrogenation of carbon, concurrently with the formation of $\mathrm{H}_{2} \mathrm{O}$.

A possible evolutionary sequence consistent with the trend of abundances in Table 2 is summarized in Table 3. 
TABLE 3

An Evolutionary Sequence FOR MANTle COMPOSITION ${ }^{\mathrm{a}}$

\begin{tabular}{|c|c|c|c|c|c|}
\hline \multirow{2}{*}{$\begin{array}{c}\text { MANTLE } \\
\text { COMPONENT }\end{array}$} & \multicolumn{5}{|c|}{ Degree of Processing } \\
\hline & None & & Mild & & Intensive \\
\hline Polar ............... & $\mathrm{H}_{2} \mathrm{O}, \mathrm{CO}_{2},\left(\mathrm{NH}_{3}\right)$ & $\rightarrow$ & $\mathrm{H}_{2} \mathrm{O}, \mathrm{CO}_{2}, \mathrm{NH}_{3}$ & $\rightarrow$ & $\begin{array}{c}\mathrm{H}_{2} \mathrm{O}, \mathrm{CO}_{2}, \mathrm{NH}_{3} \\
\mathrm{CH}_{3} \mathrm{OH}, \mathrm{XCN}\end{array}$ \\
\hline $\begin{array}{l}\mathrm{CH}_{3} \mathrm{OH}-\text { rich } . . . . . \\
\text { Nonpolar } . . . . . .\end{array}$ & $\begin{array}{c}\text { None } \\
\mathrm{CO},\left(\mathrm{O}_{2}, \mathrm{~N}_{2}\right)\end{array}$ & $\vec{\rightarrow}$ & $\begin{array}{c}\mathrm{CH}_{3} \mathrm{OH}: \mathrm{CO}_{2} \\
\mathrm{CO}, \mathrm{CO}_{2},\left(\mathrm{O}_{2}, \mathrm{~N}_{2}\right) \\
\text { Partially sublimed }\end{array}$ & $\vec{\rightarrow}$ & $\begin{array}{c}\mathrm{CH}_{3} \mathrm{OH}: \mathrm{CO}_{2} \\
\text { Sublimed }\end{array}$ \\
\hline
\end{tabular}

${ }^{a}$ Only abundant species are listed. The presence of species in parentheses is inferred.

We take Elias 16 and NGC 7538 IRS 9 as representative of pristine (unprocessed) and mildly processed ices, respectively, and the other YSOs as representative of higher degrees of processing. Pristine ices have a polar component, composed primarily of $\mathrm{H}_{2} \mathrm{O}$ and $\mathrm{CO}_{2}$, with presumably some $\mathrm{NH}_{3}$, and a nonpolar component dominated by $\mathrm{CO}$, with presumably some $\mathrm{O}_{2}$ and $\mathrm{N}_{2}$ (e.g., Tielens et al. 1991). Mild heating leads to partial evaporation of $\mathrm{CO}$ and formation of nonpolar $\mathrm{CO}_{2}$ ice mixtures and $\mathrm{CH}_{3} \mathrm{OH}: \mathrm{CO}_{2}$ complexes by annealing (Ehrenfreund et al. 1998, 1999; Gerakines et al. 1999). More intensive heating leads to further desorption of nonpolar CO: toward GL 2136, this component has been completely lost. Radiative processing, implicated in the production of XCN, is most important toward GL 7009S and W33A. Low XCN and CO abundances toward GL 2136 suggest that this line of sight has been subject to intensive heating without strong radiative processing, or that the grains have been heated sufficiently to evaporate the $\mathrm{XCN}$ carrier molecule as well as $\mathrm{CO}$.

The status of the molecular cloud(s) toward the Galactic center source Sgr A* in the evolutionary sequence described above cannot be determined reliably as the solid-phase $\mathrm{XCN}$ and $\mathrm{CO}$ abundances are unknown or poorly constrained (owing to severe contamination of the 4.5-4.8 $\mu \mathrm{m}$ region of the spectrum by strong gas-phase $\mathrm{CO}$ lines). However, the $\mathrm{CO}_{2}$ and $\mathrm{CH}_{4}$ abundances are well within the expected range, while the low $\mathrm{CH}_{3} \mathrm{OH}$ abundance is consistent with the quiescent-cloud value (see Table 2). $\mathrm{CO}_{2}$ appears to reside in an unannealed, polar ice matrix (Gerakines et al. 1999). These results give support to the view that the ices along this line of sight have not experienced significant thermal processing. The unexpectedly high $\mathrm{NH}_{3}$ abundance might be related to galactocentric variations in the abundance of elemental nitrogen (Chiar et al. 2000).

Typical abundances in cometary ices are listed in Table 2. Some general similarities with interstellar ices are evident (see recent reviews by Mumma 1997, Irvine et al. 2000, and Langer et al. 2000 for detailed discussion and comparisons). The large ranges cited in Table 2 for species such as $\mathrm{CO}$, $\mathrm{CO}_{2}$ and $\mathrm{CH}_{3} \mathrm{OH}$ reflect real comet-to-comet variations as well as uncertainties of measurement. In the case of $\mathrm{CO}_{2}$, at least one comet (Hale-Bopp) shows an abundance $(10 \%-$ $20 \%$ ) consistent with interstellar ices, while others (Halley, Hyakutake) appear to have values well below $10 \%$ (Crovisier et al. 1996; Mumma 1997; Hudson \& Moore 1999; Irvine et al. 2000). The initial abundances of both CO and $\mathrm{CH}_{3} \mathrm{OH}$ in a comet formed from interstellar ices could have a range of values, dependent on the degree of prior processing. The $\mathrm{CO}$ abundance in Hale-Bopp has been estimated by DiSanti et al. (1999) to be $\sim 12 \%$ relative to $\mathrm{H}_{2} \mathrm{O}$ for ices stored in the nucleus, consistent with an intermediate degree of thermal processing compared with dark cloud ices. Cometary $\mathrm{CH}_{3} \mathrm{OH}$ abundances can differ by factors of up to $\sim 10$, and Mumma (1997) argues that this variation may reflect processing in ice mantles prior to their incorporation into cometary nuclei. Another possibility is that $\sim 2 \%-3 \% \mathrm{CH}_{3} \mathrm{OH}$ abundances seen in many comets are representative of the solar nebula and that those comets with substantially lower values have undergone subsequent loss. Note that, in general, $\mathrm{CH}_{3} \mathrm{OH}$ abundances of $\sim 5 \%$ seem to be more typical of interstellar ices than the unusually large values seen toward GL 7009S and W33A (Allamandola et al. 1992; Chiar et al. 1996; Brooke, Sellgren, \& Geballe 1999). It is thus probable that interstellar ices subsumed by the solar nebula were less processed than those in the vicinity of massive protostars such as GL 7009S and W33A. A 3\%-5\% endowment of interstellar $\mathrm{CH}_{3} \mathrm{OH}$ to the solar nebula is thus consistent with current constraints on both interstellar and cometary ices.

\section{SUMMARY AND OVERVIEW}

Ices associated with protostellar objects such as W33A and NGC 7538 IRS 9 appear to have an approximate composition of $\mathrm{H}_{2} \mathrm{O}: \mathrm{CO}_{2}: \mathrm{NH}_{3}: \mathrm{CH}_{4} \approx 100: 17: 14: 3$ in the polar phase, considering only securely identified species that show some evidence for consistency between different lines of sight. $\mathrm{CO}_{2}, \mathrm{NH}_{3}$, and $\mathrm{CH}_{4}$ appear to be intimately mixed with the water and likely formed simultaneously by grain surface reactions. Other important constituents of the ices include $\mathrm{CH}_{3} \mathrm{OH}, \mathrm{XCN}$ (cyanate?), $\mathrm{CO}, \mathrm{OCS}, \mathrm{H}_{2} \mathrm{CO}$, and $\mathrm{HCOOH}$. Of these, $\mathrm{CH}_{3} \mathrm{OH}$ is at least partially segregated from the polar phase in the ices and appears likely to have formed, along with XCN, by thermal or energetic processing. The volatile nonpolar phase is composed primarily of $\mathrm{CO}$, presumably mixed with $\mathrm{O}_{2}, \mathrm{~N}_{2}$, and perhaps $\mathrm{CO}_{2}$.

Future work should include a systematic study of the $\mathrm{NH}_{3}$ inversion mode at $9 \mu \mathrm{m}$ in a greater sample of protostellar spectra and in field star spectra. This will establish whether the $\sim 13 \%-15 \% \mathrm{NH}_{3}$ abundance suggested by two lines of sight is generally characteristic of interstellar ices in the solar neighborhood. Adopting the most appropriate $\mathrm{H}_{2} \mathrm{O}: \mathrm{NH}_{3}$ ratio in laboratory comparisons may well hold the key to interpreting the observed $3 \mu \mathrm{m}$ feature, as $\mathrm{H}_{2} \mathrm{O}: \mathrm{NH}_{3}$ complexes contribute to the long-wavelength wing as well as modify the profile shape in the $\mathrm{N}-\mathrm{H}$ stretch region near $2.95 \mu \mathrm{m}$. It will also be important to confirm whether real differences in solid $\mathrm{NH}_{3}$ abundance exist, comparing solar neighborhood molecular clouds with those toward the Galactic center.

We hope our results may also stimulate further laboratory work aimed at investigating in detail the evolution of 
realistic interstellar ice analogs. It will be particularly important to establish, for example, whether processing of an appropriate $\mathrm{H}_{2} \mathrm{O}: \mathrm{CO}_{2}: \mathrm{NH}_{3}: \mathrm{CH}_{4}$ mixture (as constrained by the observational data now available) leads to production of $\mathrm{CH}_{3} \mathrm{OH}$ and $\mathrm{CN}$-bearing compounds under astrophysically realistic conditions.

D. C. B. W. is funded by NASA through JPL contract 961624 (ISO data analysis) and by the NASA Exobiology and Long-Term Space Astrophysics programs (grants NAG5-7598 and NAG5-7884, respectively). J. E. C. is supported by the Long Term Space Astrophysics program under NASA grant 399-20-61-02. P. A. G. holds a National Research Council Research Associateship at NASA Goddard Flight Center. We are grateful to Albert Nummelin for helpful discussions and to the referee, John Lacy, for constructive comments.

\section{REFERENCES}

Allamandola, L. J., Sandford, S. A., Tielens, A. G. G. M., \& Herbst, T. M. 1992, ApJ, 399, 134

Bernstein, M.P., Sandford, S. A., \& Allamandola, L. J. 1997, ApJ, 476, 932

Bernstein, M. P., Sandford, S. A., Allamandola, L. J., Chang, S., \& Scharberg, M. A. 1995, ApJ, 454, 327

Bird, M. K., Huchtmeier, W. K., Gensheimer, P., Wilson, T. L., Janardhan, P., \& Lemme, C. 1997, A\&A, 325, L5

Boogert, A. C. A., et al. 1996, A\&A, 315, L377

Boogert, A. C. A., Helmich, F. P., van Dishoeck, E. F., Schutte, W. A., Tielens, A. G. G. M., \& Whittet, D. C. B. 1998, A\&A, 336, 352

Boogert, A. C. A., et al. 2000, A\&A, 353, 349

Brooke, T. Y., Sellgren, K., \& Geballe, T. R. 1999, ApJ, 517, 883

Brooke, T. Y., Sellgren, K., \& Smith, R. G. 1996, ApJ, 459, 209

Capps, R. W., Gillett, F. C., \& Knacke, R. F. 1978, ApJ, 226, 863

Cernicharo, J., Kahane, C., Guelin, M., \& Gomez-Gonzalez, J. 1988, A\&A, 189, L1

Chiar, J. E., Adamson, A. J., Kerr, T. H., \& Whittet, D. C. B. 1995, ApJ, 455,234

Chiar, J. E., Adamson, A. J., \& Whittet, D. C. B. 1996, ApJ, 472, 665

Chiar, J. E., Gerakines, P. A., Whittet, D. C. B., Pendleton, Y. J., Tielens,

A. G. G. M., \& Adamson, A. J. 1998, ApJ, 498, 716

Chiar, J. E., et al. 2000, ApJ, submitted

Cottin, H., Gazeau, M. C., \& Raulin, F. 1999, Planet. Space Sci., 47, 1141

Crovisier, J., et al. 1996, A\&A, 315, L385

Dartois, E., Schutte, W., Geballe, T. R., Demyk, K., Ehrenfreund, P., \& d'Hendecourt, L. 1999, A\&A, 342, L32

de Graauw, Th., et al. 1996, A\&A, 315, L49

Demyk, K., Dartois, E., d'Hendecourt, L., Jourdain de Muizon, M., Heras, A. M., \& Breitfellner, M. 1998, A\&A, 339, 553

DiSanti, M. A., Mumma, M. J., Dello Russo, N., Magee-Sauer, K., Novak, R., \& Rettig, T. W. 1999, Nature, 399, 662

d'Hendecourt, L., et al. 1996, A\&A, 315, L365

d'Hendecourt, L., Jourdain de Muizon, M., Dartois, E., Demyk, K., Ehrenfreund, P., \& Heras, A. 1998, in The Universe as Seen by ISO (ESA Conference Publication SP 427), (Paris: UNESCO), 437

Ehrenfreund, P., Dartois, E., Demyk, K., \& d'Hendecourt, L. 1998, A\&A, 339, L17

Ehrenfreund, P., \& van Dishoeck, E. F. 1998, Adv. Space Res., 21, 15

Ehrenfreund, P., et al. 1999, A\&A, 350, 240

Gerakines, P. A., Schutte, W. A., Greenberg, J. M., \& van Dishoeck, E. F. 1995, A\&A, 296, 810

Gerakines, P. A., et al. 1999, ApJ, 522, 357

Goldsmith, P. F., Irvine, W. M., Hjalmarson, A., \& Ellder, J. 1986, ApJ, 310,383

Goss, W. M., Matthews, H. E., \& Winneberg, A. 1978, A\&A, 65, 307

Grim, R. J. A., Baas, F., Geballe, T. R., Greenberg, J. M., \& Schutte, W. 1991, A\&A, 243, 473

Grim, R. J. A., \& Greenberg, J. M. 1987, ApJ, 321, L91

Hagen, W., Tielens, A. G. G. M., \& Greenberg, J. M. 1981, Chem. Phys., 56, 367

Hirota, T., Yamamoto, S., Mikami, H., \& Ohishi, M. 1998, ApJ, 503, 717

Hudson, R. L., \& Moore, M. H. 1999, Icarus, 140, 451

Irvine, W. M., Schloerb, F. P., Crovisier, J., Fegley, B., \& Mumma, M. J. 2000, in Protostars and Planets IV, ed. V. Mannings, A. Boss, \& S. Russell (Tucson: Univ. of Arizona Press), in press
Kawaguchi, K., Ohishi, M., Ishikawa, S., \& Kaifu, N. 1992, ApJ, 386, L51

Keane, J. V., Tielens, A. G. G. M., Boogert, A. C. A., Schutte, W. A., \& Whittet, D. C. B. 2000a, A\&A, submitted

Keane, J. V., et al. 2000b, A\&A, submitted

Kerkhof, O., Schutte, W. A., \& Ehrenfreund, P. 1999, A\&A, 346, 990

Lacy, J. H., et al. 1984, ApJ, 276, 533

Lacy, J. H., Faraji, H., Sandford, S. A., \& Allamandola, L. J. 1998, ApJ, 501, L105

Langer, W. D., van Dishoeck, E. F., Bergin, E. A., Blake, G. A., Tielens, A. G. G. M., Velusamy, T., \& Whittet, D. C. B. 2000, in Protostars and Planets IV, ed. V. Mannings, A. Boss, \& S. Russell (Tucson: Univ. of Arizona Press), in press

Merrill, K. M., Russell, R. W., \& Soifer, B. T. 1976, ApJ, 207, 763

Mitchell, G. F., Allen, M., \& Maillard, J.-P. 1988, ApJ, 333, L55

Mitchell, G. F., Maillard, J.-P., Allen, M., Beer, R., \& Belcourt, K. 1990, ApJ, 363, 554

Mumma, M. J. 1997, in ASP Conf. Ser. 122, From Stardust to Planetesimals, ed. Y. V. Pendleton \& A. G. G. M. Tielens (San Francisco: ASP), 369

Nummelin, A., et al. 2000, ApJ, in press

Palumbo, M. E., Geballe, T. R., \& Tielens, A. G. G. M. 1997, ApJ, 479, 839

Palumbo, M. E., Strazzulla, G., Pendleton, Y. J., \& Tielens, A. G. G. M. $2000, A p J$, in press

Palumbo, M. E., Tielens, A. G. G. M., \& Tokunaga, A. T. 1995, ApJ, 449, 674

Pendleton, Y. J., Tielens, A. G. G. M., Tokunaga, A. T., \& Bernstein, M. P. 1999, ApJ, 513, 294

Schilke, P., Walmsley, C. M., Pineau des Forets, G., Roueff, E., Flower, D. R., \& Guilloteau, S. 1992, A\&A, 256, 595

Schutte, W. A., et al. 1996a, A\&A, 315, L333

Schutte, W. A., Gerakines, P. A., Geballe, T. R., van Dishoeck, E. F., \& Greenberg, J. M. 1996b, A\&A, 309, 633

Schutte, W. A., \& Greenberg, J. M. 1997, A\&A, 317, L43

Schutte, W. A., Tielens, A. G. G. M., \& Sandford, S. A. 1991, ApJ, 382, 523

Schutte, W. A., et al. 1998, A\&A, 337, 261

. 1999, A\&A, 343, 966

Skinner, C. J., Tielens, A. G. G. M., Barlow, M. J., \& Justtanont, K. 1992, ApJ, 399, L79

Smith, R. G., Sellgren, K., \& Tokunaga, A. T. 1989, ApJ, 344, 413

Tegler, S. C., Weintraub, D. A., Rettig, T. W., Pendleton, Y. J., Whittet, D. C. B., \& Kulesa, C. A. 1995, ApJ, 439, 279

Teixeira, T. C., Devlin, J. P., Buch, V., \& Emerson, J. P. 1999, A\&A, 347, L19

Tielens, A. G. G. M., Allamandola, L. J., Bregman, J. D., Goebel, J., d'Hendecourt, L. B., \& Witteborn, F. C. 1984, ApJ, 287, 697

Tielens, A. G. G. M., \& Charnley, S. B. 1997, Origins Life Evol. Biosphere, 27,23

Tielens, A. G. G. M., Tokunaga, A. T., Geballe, T. R., \& Baas, F. 1991, ApJ, 381,181

van Dishoeck, E. F., \& Blake, G. A. 1998, ARA\&A, 36, 317

van de Bult, C. E. P. M., Greenberg, J. M., \& Whittet, D. C. B. 1985 , MNRAS, 214, 289

Whittet, D. C. B., et al. 1996, ApJ, 458, 363

. 1998, ApJ, 498, L159

Willner, S. P., et al. 1982, ApJ, 253, 174 